\title{
Susanna, um documento histórico e poético
}

\author{
Simone Gonçalves
}

"Aqui morava Gertrud Kolmar, nome civil Chodziesner, nascida em 1894, deportada em 1943, assassinada em Auschwitz". Essa inscrição se encontra em uma das inúmeras plaquinhas espalhadas por Berlim, revestidas de latão e incrustadas nas calçadas diante das antigas moradias das vítimas do nazismo. A placa memorial, na tradução literal "pedra-tropeço", não escapa à vista do pedestre que passa pela Münchener Straße 18a, no bairro Schöneberg.

Gertrud Kolmar, que escolheu o nome alemão da cidade Chodzie ¿, na fronteira com a Polônia, como pseudônimo, cresceu no ambiente prussiano de judeus assimilados, o qual seu primo Walter Benjamin imortalizou em Infância em Berlim por volta de 1900. O conto "Susanna" foi escrito em um apartamento em Berlim, de 29 de dezembro de 1939 a 13 de fevereiro de 1940, época de completa privação de direitos e crescente ameaça. Esse foi o último texto da autora.

A história é contada rapidamente: a narradora personagem vai trabalhar como preceptora de uma garota com doenças psíquicas, em uma cidadezinha no Leste alemão, atividade exercida também pela autora, mais conhecida como poetisa, que cuidava da educação de crianças deficientes. A ação se desenrola nos diálogos entre as duas, marcados pela diferença das respectivas interpretações da realidade como também da linguagem, uma expansiva fantástica, mas ao mesmo tempo precisa, a outra limitada, prosaica, racional. A biografia de Gertrud Kolmar é inseparável deste conto, cuja envelhecida preceptora anos mais tarde se recordaria da menina Susanna, enquanto suas malas esperavam pelo segundo Affidavit de Massachusetts. O Affidavit era uma declaração por escrito sob juramento de um cidadão americano, parente consanguíneo, responsabilizando-se financeiramente por um imigrante. Judeus que queriam sair da Alemanha às vésperas do Holocausto tinham de apresentar esse documento nos Consulados americanos. 
Esse texto lúcido em sua dupla perspectiva da realidade reúne em si um documento histórico e poético ao mesmo tempo.

Uma das dificuldades recorrentes na tradução da língua alemã consiste em apreender o sentido de suas partículas gramaticais - palavras invariáveis, não flexionadas com peso semântico, mas sem função sintática - e procurar equivalências em português. Na oração "Er leugnete wohl ihr Einsamsein", optei por "Provavelmente ele negava a solidão dela". "Wohl" aqui entendo como probabilidade, suposição; para "weil ich nun einmal da war" optei por um advérbio de modo "uma vez que eu simplesmente estava lá"; e "Milda Morawe sollte nicht erst aus der Küchentür schauen" por "Pois justamente Milda Morawe não devia ver pela porta da cozinha".

Em português suprimi o discurso indireto, expresso em alemão pelo modo subjuntivo em "Und verwarf seine Meinung, daß die Waise keiner menschlichen Freunde bedürfe", optando pelo imperfeito do indicativo em vez do futuro do pretérito, "e desaprovei sua opinião de que a órfã não precisava de seres humanos como amigos" porque em português me parece redundante ressaltar que a opinião não é do sujeito que desaprova.

Em geral alterei a pontuação ao transpor para o português, ligando orações por conjunções que no original estão separadas por um ponto ou separando-as por uma vírgula no lugar do ponto. No primeiro parágrafo da parte III eliminei a conjunção "e" no início da oração "Duvidei da perspicácia do tutor e desaprovei" (Und ich zweifelte und verwarf) por me soar pesado seu emprego duas vezes na mesma oração, por já tê-la utilizado no início do mesmo parágrafo em lugar do ponto, como também em "criança crescida e afável" (freundliches erwachsenes). Essa liberdade de alterar a pontuação me parece necessária na constante "negociação" que consiste traduzir; trocando em miúdos, é um toma lá, dá cá, com o objetivo de manter a mesma leveza da linguagem tal como no original.

Nos diálogos, optei pelo português coloquial do Brasil, infringindo as regras gramaticais com a mistura dos pronomes da segunda e terceira pessoa, com a finalidade de manter o vigor, a familiaridade e informalidade da linguagem de duas pessoas que se tuteiam em alemão.

No décimo quarto parágrafo da parte III, em "Ele é um animal completamente puro, completamente delicado, quando tocado como uma água-viva mansa." (Er ist ein gan₹ reines, ganz zartes Tier und, wenn man ihn anrübrt, wie Quallen), inventei a denominação "água-viva mansa" por considerar necessário o acréscimo de "mansa", já que em português a associação com água-viva é em geral de mal-estar e em alemão a imagem no texto é sensorial e agradável, evocando na memória do leitor as águas-vivas do Mar Báltico que não queimam. 


\section{Susanna ${ }^{1}$}

Gertrud Kolmar

III

Ich hatte mir meine Aufgabe schwieriger vorgestellt. Ich hatte ein launenhaftes, leicht erregbares Wesen erwartet, mit Ablehnung und Verstocktheit zu kämpfen gedacht. Nun sollte ich nur ein erwachsenes freundliches Kind behüten. Und ich zweifelte an dem Scharfblick des alten Vormunds und verwarf seine Meinung, daß die Waise keiner menschlichen Freunde bedürfe. Er leugnete wohl ihr Einsamsein, weil der Gedanke daran ihn sonst in seiner Junggesellenbehaglichkeit störte. Das war an den allerersten Tagen; dann sah ich: er hatte recht und ich irrte. Susanna brauchte mich nicht. Sie nahm mich an und fügte mich in ihre Welt, weil ich nun einmal da war, doch sie hatte mich nicht herbeigesehnt und hätte mich kaum vermißt; sie hätte sich, wie mit mir, mit der Hündin, den Muscheln, dem Turmalin und ihrem Fischadler unterhalten. Oder auch mit der Spinne wie Christian der Zweite im Turm.

Den Christian von Dänemark und die Spinne fanden wir in einem dicken Wälzer, den Susanna aus dem Wohnstubenschrank hinauf in ihr Zimmer brachte. Denn an den langen Abenden strickten und stickten, nähten und stopften wir und lasen uns ab- wechselnd vor. Susanna liebte die Bücher, doch hatte sie eine eigene Art, mit ihnen umzugehen. Am Anfang anfangen und mit dem Ende enden, das lag ihr nicht. Für lange Geschichten, Entwicklungen, Wirrnis und Lösung hatte sie kein Verständnis. Wir versuchten es erst mit einem Roman; das blieb vergebliches Tun: das Spannende eben, das Ungewißlassen, Hinausschieben einer Entscheidung ermüdete sie; der Zusammenhang des Gesamten entging ihr.

„Die Zigeuner kommen ja gar nicht mehr vor? Bloß immer Traudel und Hans und der Grenzstreit. Das ist langweilig."

So wählte ich meist nur kleine Erzählungen, Märchen und Sagen, Abschnitte aus Reiseberichten, Geschichts- und Naturkundewerken, oftmals auch aus der Bibel.

1 Mit einem Nachwort von Thomas Sparr, Jüdischer Verlag im Suhrkamp Verlag.

Diese Erzählung erschien erstmals in der von Karl Otten herausgegebenen Anthologie Das leere Haus. Prosa jüdischer Dichter, Stuttgart 1959 [Este conto foi publicado pela primeira vez na antologia publicada por Karl Otten, Das leere Haus [A casa vazia]. Prosa de poetas judeus, Stuttgart, 1959.] 
Nämlich: „Fina hat gesagt: „Man muß jedes Buch von der ersten Seite an lesen. Bloß die Bibel nicht. Die kann man aufschlagen, wo man will; da ist alles Anfang und Ende. Weil es Gottes Wort ist."

Fina, das war die Kinderfrau Seraphine.

Wir hatten uns eines Abends in meine Stube gesetzt, und Susanna erzählte ihr selbsterdichtetes Märchen. Da war eine böse Stiefmutter, die ihre arme Stieftochter quälte, doch das Mädchen hatte den weißen Hund, der überwehte es ganz und gar mit seinen langen, feinen Haaren; es wurde unerkennbar bepelzt und selbst ein Tier. Und es brauchte nur immer zu sprechen:

Zoe, Zoe, schüttle dich,

Wirf weiße Flocken über mich!

Susanna stand plötzlich auf, knipste die Lampe aus und zog den Vorhang vom Fenster.

„Sieh, wie schön! Wir wollen jetzt noch spazieren gehen, ja? Wir sind doch heute den ganzen Tag nicht draußen gewesen. Zoe nehmen wir mit."

Ich widerstrebte zunächst; ein Nachtgang war ungewohnt, und der Himmel sprach Frost. Dann stahlen wir uns mit Diebesschlich in den Garten. Denn Milda Morawe sollte nicht erst aus der Küchentür schauen; sie hätte unser Wandergelüst schweigsam mißbilligt.

Das Himmelsgewölbe war finsterer Stein, mitleidslos reine Härte. Unzählige Sterne erstarrten zu blitzenden, splitternden Eiskristallen. Der Mond blinkte silbern und kalt. Neuschnee gefror, verkrustete mit starkem bläulichem Schein. Vor seiner Bleiche verfahlte das Tier, bebte und ward ein Schemen und schwand und irrte im Dunkel der Felder.

Unsere Pelzstiefel sanken ein. Susanna fragte:

„Weißt du, worauf wir treten? Weißt du, was das ist?"

„Schnee, Neuschnee”

„Nein. Was wir fühlen, ist Seesand. Er schimmert weiß, weil der Mond bis zu uns in die Tiefe scheint. Denn wir gehen auf dem Grunde des Meeres."

„Wie kommen wir aber dahin?”

„Wir sind ertrunken. Wir sind hinausgefahren auf einem schönen Schiff; es stieß auf eine Klippe und sank; dort liegt es. Dort liegen alle." 
Sie wies auf das Haus weit hinter uns, auf die Stadt: die lag wie ein unheimlicher Schiffsfriedhof da, und einzelne Türme ragten wie Dampferschlote und andere wie Spitzen von Masten.

„Was so kühl an unsere Gesichter streicht, ist Wasser. Und siehst du auch, was da schwimmt?"

Sie riß meinen Ärmel, als sei sie wirklich von etwas Seltsamem, Wunderbarem erregt.

„Es hat einen spitzen, langen Fischkopf und ist ganz von dichtem, farblosem Haar wie von weißlichem Tang überwachsen; aber das ist kein Tang und das ist kein Haar, das sind Tastfäden. Es ist ein Meerhund."

„Seehunde kenne ich, einen Meerhund kenne ich nicht.”

„Nein. Er steht auch in keinem Buch; keiner hat ihn entdeckt und beschrieben. Denn er lebt in der Tiefe und darf nicht hoch. Wenn er aufsteigt und ihn ein Sonnenstrahl trifft, stirbt er gleich und zerfällt und verwest und stinkt - o scheußlich!” Sie schüttelte sich. „Nur Tote können ihn sehn. Er ist ein ganz reines, ganz zartes Tier und, wenn manihn anrührt, wie Quallen -'Hör' auf, Susanna. Wir wollen umkehren. Sonst glauben wir schließlich noch beide an deine Geschichten.”

„Ich kann nicht umkehren. Mein Schiff ist in Trümmern. Und meine Kleider zerfasern und fallen mir ab; aber ich bin nicht nackt... ich wehe so... in einem Wasserschleier... Und der Meerkönig kommt und sieht mich und findet mich schön. Weißt du, wie der Meerkönig ist? Seine Brust ist mit schwarzgrünen Algen ganz buschig verpelzt, und sein Kopf ist so glatt und rund geschliffen wie die Steine am Strand. Und er trägt als Kronreif zwei silberne Fischchen, die beißen eins und das andere in den Schwanz."

„Woher du nur alles weißt ... ?”

„Von Gott. Man kann ihn nicht hören, man kann ihn nicht sehen; aber er macht, daß man alles weiß. Er hat auch den Meerkönig gemacht. Wie die Menschen."

"Davon steht aber nichts in der Bibel.” „Das ist gleich, Fina hat gesagt, auch wenn es nicht in der Bibel genannt wird, ist es von Gott. Alles Geschaffene ist Gottes. Denn der Böse kann gar nichts schaffen, sondern immer nur alles verderben. Darum, wenn ein Geschöpf überhaupt da ist, ist es von Gott.”

„Ist denn der Meerkönig überhaupt da??"

„Du bist dumm.”

Ich lachte. „Und du bist nicht sehr höflich.” 
„Wir wollen nach Hause gehen. Ich will mich schlafen legen und auf den Meerkönig warten. Er kommt nur nachts.

"Märchenfrau..."

„Das ist kein Märchen”, sagte sie ernst.

Wir gingen nach Hause.

Während ich wieder mühsam das Schloß vor die Knüppeltür zwängte, lief und schnupperte Zoe an Abfallgrube umher. Milda Morawe stand im Dunkel mit ihrem Mülleimer da als ein steinbildgewordener Vorwurf.

Ein Stuhl war umgefallen. Oder ein hölzernes Ding war auf die Dielenbretter geschlagen Das hatte mich aufgeweckt. Ich richtete mich im Bette empor und horchte.

Alles war still. Ich mochte mich irren. Vielleicht war vom Dachfirst ein Schneeklumpen abgerutscht. ich horchte. Alles blieb still. Ich warf mich zurück und streckte mich wohlig und wollte gleich wieder einschlafen - da! Ein Tappen... Was war das? Milda Morawe war das nicht. Die wäre mit wuchtigerem Tritt aus ihrem Dachkämmerchen zur Küche heruntergeholpert.Das ging ganz leise, so schleichend... Diebe? Ich erschrak. Der Hund schlug nicht an. Aber er bellte nie... Ich hob mich im Dunkel, tastete nach meinem Morgenrock und trat hinaus in den Flur.

Und ich sah. Susannas Tür stand weit offen...

Susanna war unten. Was tat sie? Sie wandelte im Schlaf durch die Räume... Sie war erwacht, war irr und suchte den Meerkönig, ihren Spuk... Ein Grausen vor der Wahnsinnigen flatterte hinter mir in der Nacht, eine höhnende Angst.Ich wollte zurück, in mein Zimmer stürzen, den Schlüssel umdrehen zweimal. Ich hätte Licht machen sollen. Aber ich blieb wie gebannt...

Nach einigen Augenblicken wurde ich ruhig, raffte mich zusammen und stieg behutsam Treppab. Unten hörte ich reden. Susannas Stimme, halblaut, und die flüsternde eines Mannes. Ich fühlte mein Herz. Ich kam zur Küche, da klaffte die Tür, und ich starrte...

Kälte wehte mich an. Das Fenster war aufgerissen. Und auf dem Fensterbrett stand Susanna, hielt die Hände am Gitter, preßte den Leib an die Stäbe und drängte hinaus. Ihr schwarzes Haar atmete wie ein Tier. Sie stand in dem langen Seidenhemd, das perlweiß schimmerte unter dem eisig silbernen Monde. Mit nackten Füßen stand sie und bebte und lachte leise und lockte.

Der Mann stand etwas tiefer im Garten. Sie verdeckte ihn mir. Nur wenn sie sich bog, erspähte ich ein Stück seines Hutes. Er sprach gedämpft; aber das Schweigen der Nacht ließ jedes Wort zu mir. 
Es war ein dunkles Flehen! ...:

„Susanna!...”

„Was nun?”

„Ich bitte dich... ich bitte dich: geh!”

Sie lachte.

„Ich will aber nicht.”

„Du frierst und wirst dich erkälten.”

„Ich friere gar nicht. Aber zu zitterst vor Frost und möchtest nach Hause.”

„Susanna... du weißt doch... warum verspottest du mich?”

„Weil du böse bist und mich wegschickst. Und ich bin doch gekommen, dir Freude zu machen."

„Mir Freude zu machen... Hol dir den Mantel... bitte... in diesem dünnen Hemd..."

„Siehst du mich so nicht gerne?"

„Du marterst mich.” anziehen."

„Du sollst dich nicht martern. Ich werde gleich gehen und mir den Mantel

„Frier dich wirklich nicht?”

„Nein.”

„Dann... bleibe einen Augenblick bleibe noch... bitte...”

Ein kleines Lachen.

„Du weißt nicht, was du willst.”

„Oh, ich weiß... ich weiß, was ich will... Susanna!...” Der Name war wie das Lächeln eines, der erstickt.

"Ja?"

„Beug dich... ich muss dir ins Ohr sagen, was ich will...”

Sie neigte sich etwas.

„Ich...... o ich... ich vergehe..ich brenne so... meine Kleider verbrennen... ich will mir alles herunterreißen... vor dir... in der Winternacht... du... ach du..."

Sie streckte den Arm durch die Stäbe.

„Komm.”

Ich erschrak. Ich fühlte, daß mir der Schweiß aus den Poren brach. Und ich stand und starrte... 
„Mein Edelstein... ja, das bist du: mein Edelstein... mein tiefroter... Rubin... "Ich bin nur noch Blut und Glühen... Susanna..."

Sie bückte sich, kniete und tat irgend etwas; ich sah aber nicht. was es war. „Das dicke Halstuch muß weg... und der Kragen...

warte...der Knopf... so...”

Stille. Brust?"

„Tust du das gern, Susanna? Streichelst du gern den Haarflaum auf meiner

„Das ist doch kein Haar. Das sind Algen. Schwarzgrüne Algen. Du bist doch ein Meerwesen. Aber niemand weiß es, weil du darüber Kleider trägst wie die wie die Menschen. Niemand weiß es. Nur ich.

"Nur du."

"Was tust du?"

„Deine Hand... Sie ist wie ein kleines, warmes Tierchen auf meiner Brust...Ich muß sie küssen...

"Ja, meine Hand ist warm; nur die Füße werden mir kalt..."

„Bistdu barfuß gekommen?”

„Nein. Meine Morgenschuh`stehen irgendwo in der Küche. Ich kann nicht mehr knien. Mach den Kragen zu... ordentlich... keiner darf sehen, wer du bist, keiner..."

Sie richtete sich empor.

„Gib deinen Fuß... ich will ihn wärmen... ihn mit meinen Händen bedecken und mit meinen Lippen... was hastdu für reizende Füße, Susanna... so weiß...."

„Haben nicht alle Frauen so weiße Füße?”

„Nicht alle... Ach du... Ich möchte dich nehmen... ganz... nicht nur deine Füße, dich ganz bedekken... ach... geh'..."

"Ja, ich friere..."

„Du frierst? Geh, Liebes... geh...”

Sie hockte nieder, sie kroch in sich zusammen, und ihr Gesicht suchte am Gitter entlang. Und ich sah einen Augenblick seinen Kopf an dem ihren, und beide waren eins... 


\section{Susanna}

Gertrud Kolmar

III

Tinha imaginado minha tarefa muito mais difícil. Esperava um ser caprichoso, facilmente irritável, e pensara que teria de lutar contra rejeição e impertinência. Mas agora eu devia tomar conta de uma criança crescida e afável. Duvidei da perspicácia do tutor e desaprovei sua opinião de que a órfã não precisava de seres humanos como amigos. Provavelmente ele negava a solidão dela porque de outro modo esse pensamento perturbava o conforto de sua vida de solteiro. Isso foi nos primeiros dias; mas então vi: ele tinha razão e eu havia me enganado. Susanna não precisava de mim. Ela me aceitou e me integrou no seu mundo, uma vez que eu simplesmente estava lá, mas não tinha desejado a minha presença e mal teria sentido a minha falta; do mesmo modo como conversava comigo, ela conversaria com a cadela, as conchas, a turmalina e com sua águia-pescadora ou também com a aranha, como Cristiano II na torre.

O Cristiano da Dinamarca e a aranha encontramos em um calhamaço que Susanna levou do armário da sala de estar para o seu quarto lá em cima. Pois nas noites compridas tricotávamos e bordávamos, costurávamos, remendávamos e líamos revezando-nos. Susanna adorava os livros, mas tinha um jeito particular de lidar com eles. Começar do começo e terminar pelo fim não lhe agradava. Para histórias longas, desenrolamentos, enredo e desfecho não tinha sensibilidade. Primeiro, tentamos com um romance; o que permaneceu em vão: justamente o suspense, a ambiguidade, o retardamento de uma decisão a cansavam; a coesão do todo lhe escapava.

- Os ciganos não aparecem mais de jeito nenhum? Sempre a mesma coisa, Traudel, Hans e o conflito de fronteiras. Isso é chato.

Assim, eu escolhia geralmente só narrativas curtas, contos de fadas e lendas, trechos de relatos de viagem, de livros de História e História natural, com frequência também da Bíblia. Como por exemplo:

- Fina disse: todo livro tem de ser lido do começo. Só a Bíblia que não, que pode ser aberta onde se quer; nela é tudo começo e fim, porque é a palavra de Deus.

Fina era a babá, Seraphine.

Uma noite sentamos no meu quarto e Susanna narrou seu conto inventado por ela mesma. Era uma madrasta malvada que judiava da sua pobre enteada, 
mas a menina tinha seu cão branco que espalhava seus pelos longos e finos cobrindo-a completamente; coberta de pelos tornava-se irreconhecível e também um animal. E só bastava dizer sempre:

Zoe, Zoe, sacode-te assim

espalha brancos flocos sobre mim!

Susanna levantou-se de repente, apagou a luz e abriu a cortina da janela.

- Olha que lindo! Vamos passear, tá? Hoje passamos o dia todo dentro de casa. Vamos levar a Zoe junto.

No início me opus; um passeio de madrugada não era costume e o céu articulava geada. Escapulimos de mansinho como ladrões para o jardim. Pois justamente Milda Morawe não devia ver pela porta da cozinha; ela teria desaprovado nosso desejo de passear.

A abóbada celeste era pedra sombria, pura dureza sem compaixão. Incontáveis estrelas petrificavam-se em cristais de gelo relumbrantes, estilhaçados. A lua brilhava prateada e fria. A neve recém-caída congelara-se formando uma crosta com um forte alumbre azulado. Diante de sua brancura, o animal empalideceu, tremeu tornando-se sombra, desaparecendo e errando na escuridão dos campos.

Nossas botas de pele afundavam. Susanna perguntou:

- Sabe onde estamos pisando? Sabe o que é isso?

- Neve, neve recém-caída.

- Não, o que estamos sentindo é areia do mar. Ela reluz branca porque o clarão da lua chega até nós atingindo a profundidade. Pois estamos indo para o fundo do mar.

- Mas como vamos chegar até lá?

- Nós nos afogamos. Partimos em um navio bonito; ele bateu num penhasco e afundou; lá está ele. Lá estão todos.

Ela apontou para a casa que ficara para trás, longe, para a cidade que lá estava como um tenebroso cemitério de navios, algumas torres se elevavam como chaminés de um vapor, outras como pontas dos mastros.

- Essa coisa fria que passa pelo nosso rosto é água. E você vê o que está nadando ali?

Ela puxou pela minha manga como se tivesse sido realmente estimulada por algo estranho, maravilhoso. 
- Tem uma cabeça de peixe longa e pontuda, é totalmente coberto de um cabelo cheio, incolor, como algas esbranquiçadas; mas não são algas nem cabelos, são fios táteis. É uma foca marítima.

- Foca marinha eu conheço, foca marítima não.

- Não, também não consta em nenhum livro; não foi descoberto nem descrito por ninguém, pois ele vive nas profundezas e não pode ir para cima. Se subir e for atingido por um raio de sol, logo morre, se decompõe, apodrece e fede - horrível! Ela estremeceu.

- Só os mortos podem vê-lo. Ele é um animal completamente puro, completamente delicado, quando tocado como uma água-viva mansa.

- Pare com isso, Susanna. Vamos voltar, senão nós duas vamos acabar acreditando nas suas histórias.

- Eu não posso voltar. Meu navio é só ruínas e minhas roupas estão se desfazendo e caindo; mas não estou nua... estou flutuando assim... em um véu d'água... E o rei das águas vem, me vê e me acha bonita. Você sabe como é o rei das águas? Seu peito é totalmente peludo de algas verdes-musgo, e sua cabeça tão lisa e redondamente polida como as pedras da praia. E como base da sua coroa ele carrega dois peixinhos prateados que mordem um o rabo do outro.

- De onde você sabe tudo isso...?

- De Deus. Não se pode ouvi-lo, não se pode vê-lo; mas ele faz com que se saiba tudo. Ele também fez o rei das águas assim como as gentes.

- Mas não tem nada disso na Bíblia.

- Tanto faz. Fina disse que mesmo que não esteja citado na Bíblia, é de Deus. Tudo que foi criado é de Deus. Pois o mal não pode criar nada, só pode estragar tudo e sempre. Por isso, se uma criatura simplesmente está aí, ela vem de Deus.

- Mas o rei das águas está mesmo aí?

- Você é burra.

Eu ri. "E você não é muito gentil."

- Vamos para casa. Quero ir dormir e esperar pelo rei das águas. Ele só vem à noite.

- Mulher de contos de fadas...

- Isto não é conto de fadas, disse séria.

Fomos para casa. 
Enquanto me esforçava para abrir o cadeado da cancela, Zoe andava e farejava para lá e para cá no buraco do lixo. Milda Morawe estava parada no escuro com seu cesto de lixo, como a imagem petrificada da repreensão.

Uma cadeira tinha caído ou algo de madeira batido no assoalho. Com isso acordei. Me levantei na cama e fiquei escutando. Estava tudo em silêncio. Pode ser que eu tenha me enganado. Talvez um monte de neve tenha escorregado da cumeeira. Eu ouvia. Tudo continuava em silêncio. Me joguei de volta na cama e me estiquei de uma maneira gostosa já queria tornar a dormir - lá! Um tatear... O que foi isso? Milda Morawe não foi. Ela teria descido com um pisar mais pesado e modos mais rudes da sua água-furtada para a cozinha. Foi bem silencioso, de mansinho.... ladrões? Me apavorei. O cachorro não reagiu. Mas ele nunca late... Me levantei no escuro, tateei procurando o meu penhoar e saí para o corredor.

E vi, a porta do quarto de Susanna estava bem aberta..

Susanna estava lá embaixo. O que ela estava fazendo? Sonambulando pelos aposentos... Ela acordara, estava ensandecida e à procura do rei das águas, do seu espírito... Um pavor diante da demente oscilava atrás de mim na noite, um medo cáustico. Queria voltar, me enfiar no quarto, passar a chave duas vezes.

Deveria ter acendido a luz. Mas fiquei como que hipnotizada...

Depois de alguns instantes me acalmei, me recompus e desci as escadas cuidadosamente. Embaixo ouvi uma conversa. A voz de Susanna meio alta e a de um homem sussurrando. Senti meu coração. Fui à cozinha, a porta se entreabriu e fixei o olhar...

O frio soprava em minha direção. A janela estava escancarada. E sobre o parapeito estava Susanna de pé, segurando a grade com as mãos, pressionava o corpo contra as barras empurrando-o para fora. Seus cabelos pretos respiravam como um animal. Estava parada com sua longa camisola de seda que brilhava como pérola branca sob a lua de prata gelada. Com os pés nus, de pé, tremia, ria baixo e seduzia.

O homem estava mais abaixo no jardim. Ela o tapava e só quando se abaixava é que eu podia entrever um pedaço do seu chapéu. Ele falava de modo abafado; mas a calada da noite permitia que toda palavra chegasse a mim.

Era uma vaga súplica:

- Susanna!...

- O quê?

- Eu te peço... eu te peço: vai!

Ela ria. 
- Mas eu não quero.

- Você está com frio e vai se resfriar.

- Eu não estou com o menor frio. Mas você está tremendo de frio e gostaria de ir para casa.

- Susanna... mas você sabe.... por que você está debochando de mim?

- Porque você é mau e me manda embora. E portanto eu vim para te alegrar.

- Para me alegrar... pega o mantô... por favor... com essa camisola fininha...

- Você não gosta de me ver assim?

- Você me martiriza.

- Você não deve se martirizar. Já vou vestir o mantô.

- Você não está mesmo com frio?

- Não.

- Então... espera... um momento espera ainda... por favor...

Um risinho.

- Você não sabe o que quer.

- Oh, eu sei... eu sei o que quero... Susanna!" O nome era como o riso de alguém sufocando.

$-\mathrm{O}$ que?

- Abaixa... preciso te dizer no ouvido o que eu quero...

Ela se inclinou um pouco.

- Eu... oh eu... estou morrendo... ardendo assim... minhas roupas estão queimando... quero arrancar tudo de mim... diante de você... nesta noite de inverno... você... ah você...

Ela esticou o braço através das barras.

- Vem.

Me apavorei. Senti meu suor saindo pelos poros. E fiquei de pé com o olhar fixo...

- Minha pedra preciosa... é isso que você é: minha pedra preciosa... meu profundo vermelho... rubi...

- Eu sou só sangue e ardor... Susanna...

Ela se agachou, ajoelhou-se e fez alguma coisa; mas eu não podia ver o quê. 
- O cachecol grosso temos que tirar... e o colarinho... espera... o botão... $\operatorname{assim} .$.

Silêncio.

- Você gosta de fazer isso, Susanna? Gosta de acariciar a penugem do meu peito?

- Mas isso não é pelo. São algas. Algas verdes-musgo, pois você é um ser marinho. Mas ninguém sabe, porque você usa roupas como pessoas. Ninguém sabe. Só eu.

- Só você.

- O que você está fazendo?

- Sua mão... é como um bichinho pequeno e quente sobre o meu peito... preciso beijá-la...

- É, minha mão está quente; só meus pés estão ficando frios.

- Você veio descalça?

- Não. Meu chinelo está em algum lugar na cozinha. Não consigo ficar mais de joelhos. Fecha o colarinho... direito... ninguém pode saber o que você é, ninguém...

- Me dá o seu pé... quero esquentá-lo, cobri-lo com as minhas mãos e meus lábios... seus pés são um encanto Susanna... tão brancos...

- Todas as mulheres não têm pés brancos assim?

- Não todas... Ah, você... queria te pegar... inteira... não só os teus pés, te cobrir completamente... ah... vai embora...

- Sim, estou com frio...

- Você está com frio? Vai, meu amor... vai

Ela acocorou-se, encolheu-se e seu rosto procurava ao longo da grade. E eu vi em um instante a cabeça de um e de outro formando uma só... 